\title{
Co-aggregation as a virulent factor of Streptococcus sanguis isolated from infective endocarditis
}

\author{
Kuniyasu Ochiai, Ken Kikuchi*, Kazuo Fukushima \\ and Tomoko Kurita-Ochiai \\ Department of Microbiology, Nihon University School of Dentistry at Matsudo, \\ Chiba 271-8587 \\ *Central Clinical Laboratory, Department of Medicine, Tokyo Woman's Medical College Hospital, \\ Shinjyuku-ku, Tokyo 162-0054
}

(Received 6 May and accepted 30 July 1999)

\begin{abstract}
The pathogenicity of strains of the Streptococcus sanguis group, isolated from infective endcarditis, was studied by measuring the development of subcutaneous abscesses in mice after infection with $S$. sanguis and Actinomyces viscosus either singly or as coaggregated pairs. The pathogenicity of the co-aggregates was also examined in various viable combinations of the two bacterial species. More abscesses were formed by $A$. viscosus than the $S$. sanguis group including clinical isolates. Abscess formation by co-aggregates of combinations of each isolate and $A$. viscosus produced a higher percentage of abscess formation than those caused by infection with a pure suspension of $A$. viscosus or tested streptococci. Co-aggregated cells were more resistant to phagocytosis and killing by neutrophils in vivo. These results indicated that $S$. sanguis group streptococci isolated from infective endocarditis are able to co-aggregate and resist phagocytosis. The ability of co-aggregation of $S$. sanguis may serve as a survival mechanism in a host defense system and may be linked with virulence of this bacteria. (J. Oral Sci. 41, 117. 122, 1999)
\end{abstract}

Key words: infective endocarditis; oral streptococci; Streptococcus sanguis group; co-aggregation.

\section{Introduction}

Infective endocarditis is frequently caused by oral alphahemolytic streptococci, such as Streptococcus (S.) sanguis, $S$. gordonii, S. mutans and S. mitis (1-3). The streptococci can enter the blood through breaks in the microcirculation of oral tissues induced by trauma, including dental manipulations, oral hygiene procedures, mastication, and oral infections (4).

Streptococci, circulating in blood, may then adhere to damaged endothelium $(5,6)$ or thrombi composed of platelets

Correspondence to Dr. Kuniyasu Ochiai, Department of Microbiology, Nihon University School of Dentistry at Matsudo, Chiba 271-8587, Japan and fibrin (5-7) on vessel walls, endocardium, and heart valves. Further, development of thrombi and verrucous vegetations on valves serve to embed the streptococci and provide protection from host defenses and antibiotic therapy $(6,7)$. Viridans group streptococci, the most common cause of bacterial endocarditis, also produce an exopolysaccharide (glycocalyx) which correlates with adherence to damaged heart valves (8). The amount of glycocalyx is correlated with the size of the infected cardiac vegetations and resistance to antimicrobial therapy (9).

Current evidence regarding the pathogenesis of bacterial endocarditis suggests that a crucial step in the development of infection is the initial adherence of bacteria to endocardium. Synthesis of glucan polymer has been correlated with the ability of $S$. sanguis to adhere to damaged heart valve leaflets in vitro and has been associated with increased infectivity in vivo (10). Dextranase-treated cells showed decreased adherence to fibrin-platelet matrix in vivo and decreased rate of infection in the animal model of endocarditis (10). Streptococcal virulence in endocarditis involves factors that promote infectivity and pathogenicity. Previous reports have shown that surface-localized glucosyltransferase mediates adhesion of S. gordonii to vein endotherial cells in vitro (11). Several species of oral streptococci have been shown to aggregate with other oral bacteria such as Actinomyces spp. and Bacterionema $s p p$. in the maturation process of dental plaque. Unusual morphological arrangements have been observed when filamentous bacteria form specific aggregates with oral streptococci in the shape of corncobs (12). It is well known that platelet aggregation and glycocalyx contribute the pathogenesis of oral streptococci in the initial step of bacterial endocarditis. However, there is little published information about the effect of co-aggregation of $S$. sanguis isolated infective endocarditis. In this study, therefore, we employed the clinical isolates to clarify the effect of coaggregation on the pathogenicity of $S$. sanguis. This study was performed to assess the pathogenicity of aggregates of $A$. viscosus and S. sanguis group streptoccocci. 


\section{Materials and Methods \\ Bacterial strains and culture conditions}

The following five viridans streptococci were used as the control strains in this study; Streptococcus sanguis ATCC10556, S. oralis strain 34, S. gordonii ATCC 10558, S. salivarius ATCC9222 and S. mitis (S. oralis) ATCC9811. Nine clinical isolates of viridans streptococci were isolated from confirmed cases of endocarditis in patients at the Department of Medicine, Tokyo Woman's Medical College. Bacterial classification was done using results from previous reports $(13,14)$. Actinomyces viscosus $\mathrm{Tl} 14 \mathrm{~V}$ was also employed in the co-aggregation experiment.

A streptomycin-resistant strain of $A$. viscosus $\mathrm{T} 14 \mathrm{~V}$ was produced in our laboratory by a series of subcultures in ToddHewitt Broth (BBL, Cockeysville, MD, USA) containing 2 $\mathrm{mg} / \mathrm{ml}$ streptomycin (Meiji Seika, Tokyo, Japan). Each culture was mixed with skimmed milk and stored frozen at $-20^{\circ} \mathrm{C}$. Cells were cultured anaerobically $\left(\mathrm{CO}_{2} 5 \%, \mathrm{~N}_{2} 95 \%\right)$ in ToddHewitt broth for $18 \mathrm{~h}$ at $37^{\circ} \mathrm{C}$. Cells were harvested by centrifugation $(1200 \times \mathrm{g}$ for $20 \mathrm{~min})$ and washed three times with buffer: $1.0 \mathrm{mM}$ Tris (hydromethyl)-aminomethane, adjusted to $\mathrm{pH} 8.0 ; 0.1 \mathrm{mM} \mathrm{CaCl}_{2}, 0.1 \mathrm{mM} \mathrm{MgCl}_{2}, \mathrm{NaN}_{3}$ $0.02 \%$ and $0.15 \mathrm{M} \mathrm{NaCl}$. Heat-treated cells $\left(85^{\circ} \mathrm{C}\right.$ for 30 $\min$ ) were also used in this study.

\section{Co-aggregation assay}

Co-aggregation was assayed by the method of Cisar et al. (15). Equal volumes $(0.2 \mathrm{ml})$ of each cell suspension were mixed for $10 \mathrm{sec}$ on a vibrator and allowed to stand at room temperature for $10 \mathrm{~min}$.

\section{Abscess development}

The method for abscess development was described previously (16). Briefly, male mice (ddy) aged 4 weeks were obtained and observed for 7 days before the experiments. Bacteria were cultured and centrifuged as described above and washed with $25 \mathrm{mM}$ potassium phosphate buffer ( $\mathrm{pH} 8.0$ ) containing $25 \mathrm{mM} \mathrm{NaCl}$. Inocula were adjusted to a density of $1.0 \times 10^{5} \sim 1.0 \times 10^{10} \mathrm{cfu} / \mathrm{ml}$ spectrophotometrically at 540 $\mathrm{nm}$, then within $15 \mathrm{~min}, 0.1 \mathrm{ml}$ was injected subcutaneously into the backs of the mice. The inocula for mixed cultures $(0.1$ $\mathrm{ml})$ consisted of equal volumes $(0.05 \mathrm{ml})$ of each species. Experiments were repeated four or five times with groups of five mice, and abscess formation was evaluated 2 days after inoculation. The mice were sacrificed with ether and abscess sizes were measured with calipers. Smears were also stained with Giemsa's solution and examined microscopically.

\section{Phagocytosis of co-aggregates by neutrophil} polymorphonuclear leukocytes (PMNs)

In vitro inhibition of phagocytosis was examined using the method described previously (16). In the experiments on the inhibition of phagocytosis and the reduction of the bactericidal activity of PMNs by actinomyces and streptococci, the ratio of test organisms that produced maximal co-aggregation with minimal free non-aggregated cells was calculated. After spectrorophotometric adjustment of each cell suspension to equal density, A. viscosus was mixed with the tested streptococcal strains. To separate non-aggregated and aggregated cells, each mixture was applied to the top of a glycerol column as described by Ochiai et al. (17). The mixture, consisting of discrete and aggregated cells, was applied to the step-gradient, glycerol column and $0.5-\mathrm{ml}$ fractions were collected from the bottom. After $10 \mathrm{~min}$, nonaggregates remained in the top layer of the column and any aggregated cells that settled in the glycerol $30 \%$ layer were determined spectrophotometrically at $540 \mathrm{~nm}$. The effect of co-aggregates on phagocytosis was investigated with PMNs induced by injecting $2 \mathrm{ml}$ of oyster glycogen $(0.1 \%$ in $2 \mathrm{mM}$ phosphate buffered saline, $\mathrm{pH}$ 7.2; Sigma, St Louis, MO, USA) into the abdominal cavity of each mouse. The mice were sacrificed with ether 10-12 h later and peritoneal exudate cells were collected by the injection of RPMI-1640 Medium (Gibco, Rockville, MD, USA) supplemented with $2 \%$ fetal calf serum into the abdominal cavity. The RPMI-1640 was aspirated and the total number of cells was determined by haemocytometer (Kayagaki Irika Kogyo Co. Ltd, Tokyo, Japan) immediately after rubbing the abdomen. The number of PMNs present in peritoneal exudate cells was determined by Giemsa staining

\section{Statistics}

The significance of differences between groups was determined by Student's $t$ test.

\section{Results \\ Co-aggregation between A. viscosus and oral streptococci}

When $A$. viscosus was mixed with the tested oral streptococci including nine strains of infectious endocarditis isolates, all the suspensions rapidly became granular and soon large clumps of bacteria formed, except for S. gordonii ATCC10558 and S. salivarius ATCC9222 (Table 1). Microscopic examination of these clumps showed that they were a mixture of the two organisms. However, non-aggregates were found when both strains were heated (Table 1).

\section{Abscesses caused by non-aggregated cells}

The results for pure bacterial suspensions injected subcutaneously into the backs of mice are shown in Fig. 1. Abscesses developed in all animals inoculated with $\geqq 1.0$ $\times 10^{7}$ cfu of $A$. viscosus $\mathrm{T} 14 \mathrm{~V}$, but this was reduced to $8.5 \%$ when an inoculum of $1.0 \times 10^{6} \mathrm{cfu}$ was used. Abscesses developed in all mice inoculated with $1.0 \times 10^{9} \mathrm{cfu}$ of all the tested $S$. sanguis including clinical isolates, in $31.3 \%$ with 1.0 $\times 10^{8} \mathrm{cfu}$ of $S$. sanguis ATCC10556, 55.4\% with $S$. sanguis TW678 and $47.2 \%$ with $S$. sanguis TW644. However, no lesions were observed at concentrations of $\leqq 1.0 \times 10^{6} \mathrm{cfu}$ when the tested strains of streptococcus were used. These abscesses were smaller than those produced by A. viscosus $\mathrm{Tl} 14 \mathrm{~V}$. Bacterial cells were present in all the stained smears of pus and the test species were isolated from the abscess samples initiated by viable bacterial suspension. 
Table 1 Coaggregation of infective endcarditis-isolated strains with Actinomyces viscosus

(A). Laboratory strain

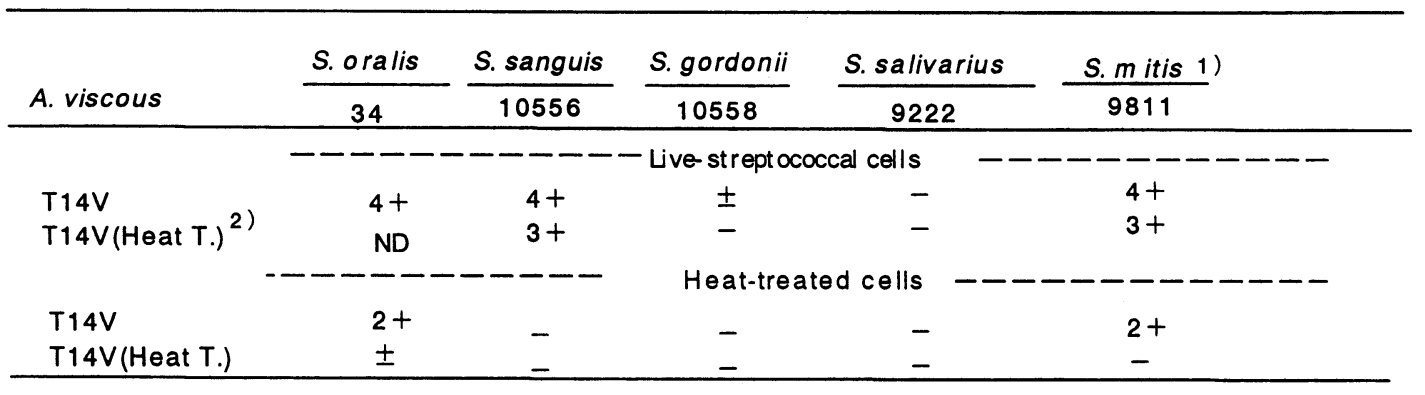

(B) Isolates from infective endocarsditis

\begin{tabular}{|c|c|c|c|c|c|c|c|c|c|c|}
\hline \multirow[b]{2}{*}{ A. viscous } & \multicolumn{4}{|c|}{ S. oralis } & \multicolumn{6}{|c|}{ S. sanguis } \\
\hline & TW 50 & TW 52 & TW & 644 & TW 142 & TW185 & TW186 & TW 675 & TW 678 & TW 681 \\
\hline & \multicolumn{7}{|c|}{--------------- Live streptococcal cells } & \multicolumn{3}{|c|}{$------\cdots-\cdots$} \\
\hline T14V & $3+$ & $4+$ & & $4+$ & + & $2+$ & $2+$ & $4+$ & $3+$ & $3+$ \\
\hline \multirow[t]{2}{*}{ T14V(Heat T.) } & $4+$ & $2+$ & & $2+$ & \pm & + & + & - & $4+$ & $3+$ \\
\hline & \multicolumn{7}{|c|}{-------------} & \multicolumn{3}{|c|}{$-\cdots-\cdots-\cdots-\cdots$} \\
\hline T14V & + & + & & - & \pm & \pm & \pm & $2+$ & + & - \\
\hline T14V(Heat T.) & - & - & & - & - & - & - & - & - & - \\
\hline
\end{tabular}

1) S. $m$ itis ATCC9811 is also classified in S. oralis.

2) Heat treated at $85^{\circ} \mathrm{C}$ for $30 \mathrm{~min}$.

\section{Abscesses caused by co-aggregates}

When co-aggregates of A. viscosus T14V $\left(1.0 \times 10^{5} \mathrm{cfu}\right)$ and various concentrations of $S$. sanguis TW678 were injected into mice, abscesses developed in $64.5 \%$ and $17.2 \%$ of animals for inocula of $1.0 \times 10^{7} \mathrm{cfu}$ and $1.0 \times 10^{8} \mathrm{cfu}$, respectively (Fig. 2A). S. sanguis TW678 was at a higher percent of cells when compared with $S$. sanguis ATCC10556 at $1.0 \times 10^{8} \mathrm{cfu}$. A similar experiment was done with A. viscosus T14V (1.0 $\times 106 \mathrm{cfu})$ and $S$. sanguis TW678. Coaggregates were injected into mice, abscesses developed in $86.8 \%, 67.9 \%$ and $29.6 \%$ of animals for inocula of $1.0 \times 10^{8}, 1.0 \times 10^{7}$ and $1.0 \times 10^{6}$ cfu, respectively (Fig. 2B). This compares with a value of $8.5 \%$ when A. viscosus was tested in pure culture under the same conditions. Raised spherical abscesses, containing yellow and sticky pus, resulted from viable bacterial injections.

\section{Anti-phagocytic action of cell aggregates}

When S. sanguis TW678 was injected into mice, $66.3 \%$ of PMLs had phagocytosed bacteria $15 \mathrm{~min}$ after inoculation, and $76.4 \%$ after $60 \mathrm{~min}$ (Fig. 3). Similar results were obtained from S. sanguis ATCC10556. For A. viscosus $\mathrm{T} 14 \mathrm{~V}$, the percentage of cells with phagocytosed bacteria was $59.6 \%, 65.2 \%$ and $74.2 \%$ after 15,30 and 90 min, respectively.

When co-aggregates of A. viscosus and S. sanguis TW678 were inoculated into the abdominal cavity of mice after coaggregation, the number of PMNs with phagocytosed bacteria was $39.4 \%$ after $15 \mathrm{~min}, 50.2 \%$ after $30 \mathrm{~min}$ and $48.2 \%$ after 90 min (Fig. 3). A significant difference ( $\mathrm{p} \leqq 0.01)$ was found between the co-aggregate and the pure culture groups of A. viscosus and S. sanguis tested at 60 and $90 \mathrm{~min}$ in vivo.

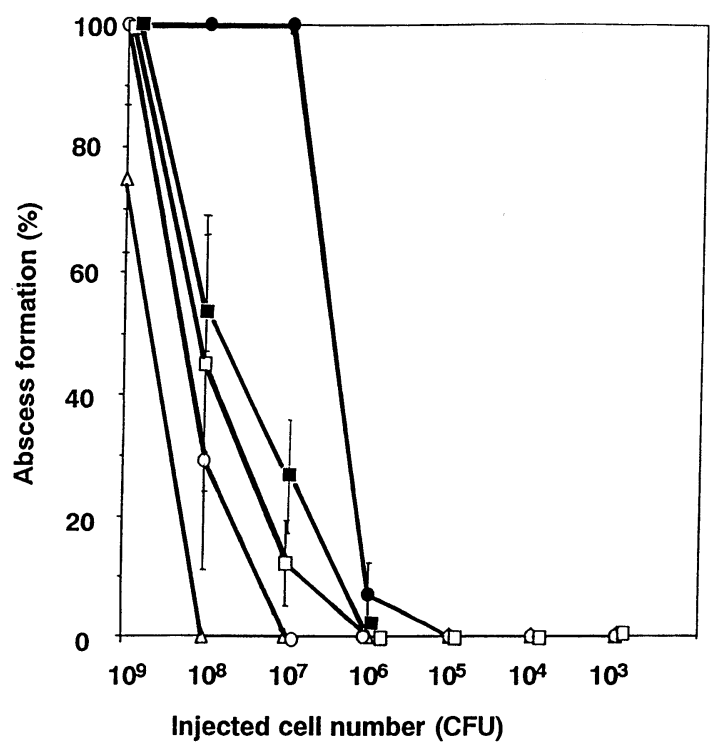

Fig. 1 Abscess formation in mice 2 days after injection of cell suspension of live strains of streptococcus and A. viscosus. Points represent the mean values from five experiments with five mice in each group; vertical bars represent the SD. Symbols represent $A$. viscosus $(\bullet)$, S. sanguis ATCC $10556(\bigcirc)$, S. salivarius ATCC $9222(\triangle)$ and strains isolated from infective endocarditis $S$. sanguis TW678 ( and $S$. oralis TW 644 ( $\square$ ). 


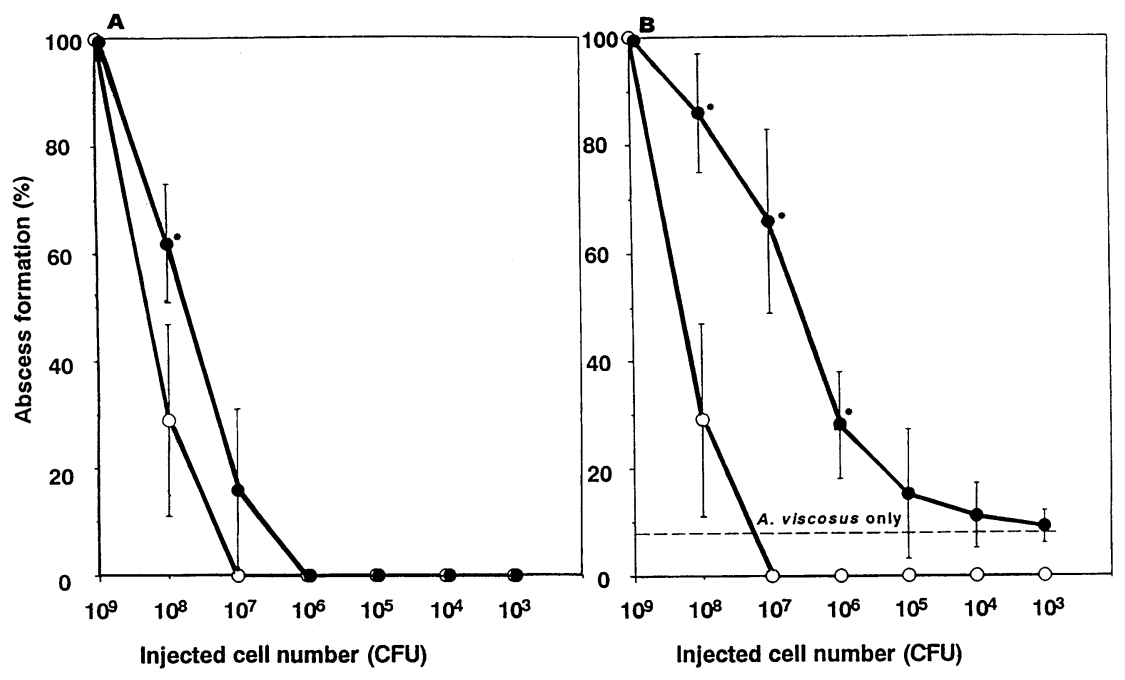

Fig. 2 The effect of co-aggregation of A. viscosus, A, $1.0 \times 10^{5} ; \mathrm{B}, 1.0 \times 10^{6}$ and various concentrations of either S. sanguis ATCC10556 or TW678 on abscess formation in mice. Strains were injected after co-aggregates had formed. Points represent the mean values from five different experiments with five mice in each group; vertical bars represent the SD. Symbols represent $A$. viscosus $+S$. sanguis ATCC10556 (O) and A. viscosus + S. sanguis TW678 (@). Values for co-aggregates were significantly higher than with A. viscosus or $S$. sanguis alone $(* \mathrm{p}<0.01)$.



Fig. 3 The effect of bacterial co-aggregates on the ability of polymorphonuclear leukocytes to act as phagocytes in vivo. Points represent the mean values from five different experiments with three mice in each group; vertical bars represent the SD. Symbols represent $S$. sanguis ATCC $10556(\bigcirc)$, S. sanguis TW678 ( $\square)$, A. viscosus $(\triangle), A$. viscosus $+S$. sanguis ATCC10556 (๑), A. viscosus $+S$. sanguis TW678 (ם). Values for co-aggregates were significantly lower than with $A$. viscosus or $S$. sanguis alone $(* \mathrm{p}<0.01)$

\section{Discussion}

Streptococcal infection of heart valves and endocardium accounts for as many as half of the cases of native valve endocarditis (18). These infections may occur when oral bacteria enter the circulatory system and adhere and colonize damaged heart tissues (19). The virulence of viridans streptococci in the pathogenesis of infective endocarditis remains an enigma. $S$. sanguis is a normal inhabitant of the human oropharynged mucosa and dental plaque. In this environment, it is considered indigenous and relatively avirulent. However, this organism may escape the oral cavity following dental or specialized procedures and enter the blood stream. The resulting bacteremia may cause infective endcarditis. Certain strains of $S$. sanguis group streptococci induce human platelets to aggregate in vitro (20). Streptococcal glycocalyx are important virulence factors in the pathogenesis of endocarditis. These surface polymers may facilitate the binding of bloodborne bacteria to valve surfaces, thereby initiating endocardial infection (21).

Bacterial surface polysaccharide and proteins mediate aggregation and co-aggregation, therefore, many of streptococci found in dental plaque also have the ability to coaggregate with A. viscosus. Co-aggregation is highly specific, where the partners of one cell type may not be partners of a closely related cell type (22). It has been reported that saliva and dextran induce aggregation in oral streptococci (23). These species exhibit both homotypic and heterotypic aggregation with the latter being related to cell-to-cell interactions between the adhesin-receptor complementary pairs on the two cell types $(15,24)$. Ochiai et al. (16) reported that $S$. mitis could evade phagocytosis by forming co-aggregate with $A$. viscosus. Aggregation of platelets by bacteria is well studied as a causative agent of oral streptococci for infective endocarditis, however, coaggregation is not well elucidated. Actinomyces 
are pathogenic bacteria that cause chronic inflammatory lesions in man and animals (25). Engel et al. (26) have reported that A. viscosus releases various extracellular inflammatory substances that cause increased migration of PMNs and accelerate tissue destruction. They also reported that inoculation of $A$. viscosus cells caused a high rate of abscess development. Co-aggregates between A. viscosus and S. sanguis (Fig. 2A and $B$ ) exhibited greater pathogenicity than that shown by single bacterial cells (Fig. 1). These results suggest that the pathogenicities of $A$. viscosus and $S$. sanguis are increased by co-aggregation. It was found that $A$. viscosus was more resistant to phagocytosis than $S$. sanguis in pure culture, and when actinomyces formed part of the co-aggregates, their uptake by PMNs was decreased further in vivo (Fig. 3). Since the ability to co-aggregate with $A$. viscosus induce $S$. sanguis to survive at a higher rate, co-aggregation of oral bacteria may inhibit phagocytosis.

Some polysaccharides from $S$. sanguis act as a receptor for a Gram-negative bacterium (27). Previous studies have shown that these Gram-negative bacteria produce immunosuppressive factors intra- and extra-cellularly (28-30). The strains of $S$. sanguis and $S$. oralis co-aggregate with Capnocytophaga $(C)$. ochracea with these polysaccharides. Recently, several reports have described periodontopathic bacteria, such as $C$. ochracea and Actinobacillus spp. as the cause of septicemia and endcarditis in compromised and compromised hosts $(31,32$, 33).

The present study reveals that $S$. sanguis could evade phagocytosis by forming co-aggregates with other oral bacteria. Coaggregation of oral bacteria would be an important virulent factor to cause systemic infection. Further investigations are required to elucidate this mechanism.

\section{Acknowledgments}

This work was supported in part by the Frontier Science from the Ministry of Education, Science, Sports and Culture of Japan (Nihon University School of Dentistry at Matsudo)

\section{References}

1. Roberts, R. B., Krieger, A. G., Schiller, N. L. and Gross, K. C. (1979) Viridans streptococcal endocarditis: the role of various species, including pyridoxaldependent streptococci. Rev. Infect. Dis. 1, 955-966

2. Sussman, J. I., Baron, E. J., Tenenbaum, M. J., Kaplan, M. H., Greenspan, J., Facklam, R. R., Tyburski, M. B., Goldman, M. A., Kanzer, B. F. and Pizzarello, R. A. (1986) Viridans streptococcal endocarditis: clinical, microbiological, and echocardiographic correlations. J. Infect. Dis. 154, 597-603

3. Young, S. G., Davee, T., Fierer, J. and Morey, M. K. (1987) Streptococcus sanguis II (viridans) prosthetic valve endocarditis with myocardial, splenic and cerebral abscesses. West. J. Med. 146, 479-481

4. Baddour, L. M., Christensen, G. D., Lowrance, J. H. and Simpson, W.A. (1989) Pathogenesis of experimental endocarditis. Rev. Infect. Dis. 11, 452-463
5. Hook, E. W. III and Sande, M. A. (1974) Role of the vegetation in experimental Streptococcus viridans endocarditis. Infect. Immun. 10, 1433-1438

6. Freedman, L. R. (1987) The pathogenesis of infective endocarditis. J. Antimicrob. Chemother. 20 A Suppl., 1-6

7. Yersin, B. R., Glauser, M. P. and Freedman, L. R. (1982) Effect of nitrogen mustard on natural history or right-sided streptococcal endocarditis in rabbits: role for cellular host defenses. Infect. Immun., 35, 320-325.

8. Dall, L., Barnes, W. G., Lane, J. W. and Mills, J. (1987) Enzymatic modification of glycocalyx in the treatment of experimental endocarditis due to viridans streptococci. J. Infect. Dis. 156, 736-740

9. Mills, J., Pulliam, L., Dall, L., Marzouk, J., Wilson, W. and Costerton, J. W. (1984) Exopolysaccharide production by viridans streptococci in experimental endocarditis. Infect. Immun. 43, 359-367

10. Scheld, W. M., Valone, J. A. and Sande, M. A. (1978) Bacterial adherence in the pathogenesis of endocarditis. Interaction of bacterial dextran, platelets, and fibrin. J. Clin. Invest. 61, 1394-1404

11. Vacca-Smith, A. M., Jones, C. A., Levine, M. J. and Stinson, M. W. (1994) Glucosyltransferase mediates adhesion of Streptococcus gordonii to human endothelial cells in vitro. Infect. Immun. 62, 2187-2194

12. Listgarten, M. A., Mayo, H. and Amsterdam, M. (1973) Ultrastracture of the attachment device between coccal and filamentous microorganisms in "corn cob" formations of dental plaque. Arch. Oral Biol. 18, 651-656

13. Kilian, M. Mikkelsen, L. and Henrichen, J. (1989) Taxonomic study of viridans streptococci: description of Streptococcus gordonii sp. nov. and emended descriptions of Streptococcus sanguis (White and Nieven 1946), Streptococcus oralis (Brigdge and Sneath 1982), and Streptococcus mitis. (Andrews and Horder 1906) Int. J. Syst. Bacteriol. 39, 471-484

14. Kawamura, Y., Hou, X., Sultana, F., Miura, H. and Ezaki. T. (1995) Detrmination of $16 \mathrm{~S}$ rRNA sequences of Streptococcus mitis and Streptococcus gordonii and phylogenic relationships among members of the genus Streptococcus. Int. J. Syst. Bacteriol. 45, 406-408

15. Cisar, J.O., Kolenbrander, P.E. and McIntire, F.C. (1979) Specificity of coaggregation reactions between human oral streptococci and strains of Actinomyces viscosus or Actinomyces naeslundii. Infect. Immun. 24, 742-752

16. Ochiai, K., Kurita-Ochiai, T., Kamino, Y. and Ikeda, T. (1993) Effect of co-aggregation on the pathogenicity of oral bacteria. J. Med. Microbiol. 39, 183-190

17. Ochiai, K., Ikeda, T. and Shiota, T. (1983) An improved method for measuring aggregation of certain streptococcal bacteria found in dental plaque. Arch. Oral Biol. 28, 253-258

18. Weinberger, I., Rotenberg, Z., Zacharovitch, D., Fuchs, J., Davidson, E. and Agmon, J. (1990) Native valve 
infective endocarditis in the 1970s versus the 1980s: underlying cardiac lesions and infecting organisms. Clin. Cardiol. 13, 94-98

19. Overholser, C. D., Moreillon, P. and Glauser, M.P. (1987) Experimental bacterial endocarditis after dental extraction in rats with periodontitis. J. Infect. Dis. 155 , 107-112

20. Verhaaren, H., Claeys, G., Verschraegen, G., de Niel, C., Leroy, J. and Clement, D. (1989) Endcarditis from a dental focus. Importance of oral hygiene in valvar heart disease. Int. J. Cardiol. 23, 343-347

21. Sullam, P.M., Valone, F. H. and Mills, J. (1987) Mechanisms of platelet aggregation by viridans group streptococci. Infect. Immun. 55, 1743-1750

22. Kolenbrander, P. E., Ganeshkumar, N., Cassels, F.J. and Hughes, C.V., (1993) Coaggregation: specific adherence among human oral plaque bacteria. FASEB J. 7, 406413

23. Malamud, D., Appelbaum, B., Kline, R. and Colub, E.E. (1981) Bacterial aggregating activity in human saliva: comparisons of bacterial species and strains. Infect. Immun. 31, 1003-1006

24. McIntire, F. C., Vatter, A. E., Baros, J. and Arnold, J. (1978) Mechanism of coaggregation between Actinomyces viscosus $\mathrm{T} 14 \mathrm{~V}$ and Streptococcus sanguis 34. Infect. Immun. 21, 978-988

25. Brown, J.R. (1973) Human actinomycosis. A study of 181 subjects. Hum. Pathol. 4, 319-330

26. Engel, D., van Epps, D. and Clagett, J. (1976) In vivo and in vitro studies on possible pathogenic mechanisms of Actinomyces viscosus. Infect. Immun. 14, 548-554

27. Cassels, F. J. and London, J. (1989) Isolation of a coaggregation-inhibiting cell wall polysaccharide from Streptococcus sanguis H1. J. Bacteriol. 171, 40194025

28. Bolton, R. W. and Dyer, J.K. (1983) Suppression of murine lymphocyte mitogen responses by exopolysaccharide from Capnocytophaga ochracea. Infect. Immun. 39, 476-479

29. Ochiai, K., Senpiku, H., and Kurita-Ochiai, T. (1998) Purification of immunosuppressive factor from Capnocytophaga ochracea. J. Med. Microbiol. 47, 1087-1095.

30. Kurita-Ochiai, T. and Ochiai, K. (1996) Immunosuppressive factor from Actinobacillus actinomycetemcomitans down regulates cytokine production. Infect. Immun. 64, 50-54.

31. Forlenza, S. W., Newman, M. G., Lipsey, A. I., Siegel, S. E. and Blachman, U. (1980) Capnocytopahga species: a newly recognized clinical entity in glanulocytopenic patients. Lancet 115, 567-568

32. Haulk, A. A., Sugar, A. M. and Rushing, J. L. (1980) Capnocytopahga septicemia. N. Engl. J. Med. 302, 922

33. Siegman-Igra, Y., Schwartz, D., Ophir, O. and Konforti, N. (1984) Endcarditis caused by Actinobacillus actinomycetemcomitans. Eur. J. Clin. Microbiol. 3, 556-559 